\title{
1.1. Detección y abordaje de problemas o tendencias actuales en el arte y el diseño
}

\section{Dosio, Patricia Andrea [ver currículum del autor, docente de la Facultad de Diseño y Comunicación]}

Abstract del proyecto:

El presente proyecto áulico contempla diferentes instancias a desarrollar a lo largo de la cursada de la materia Reflexión Artística I. Estas instancias conducen a la realización de un ensayo final que se encuadra dentro de la propuesta pedagógica (Ensayos sobre la Imagen) en la que participa la asignatura. El trabajo final a cargo de los alumnos radica entonces en expandir una investigación consistente en la captación, identificación de temas, cuestiones, líneas de trabajo o problemáticas dentro del área del diseño de cada estudiante (Diseño Industrial, Gráfico, Indumentaria, Historieta, etc.) y su puesta en relación con el tratamiento del mismo -tema, cuestión, línea de trabajo o problemática- desde el campo del arte, a partir de la obra de un artista latinoamericano emergente, de la joven generación o no consagrado. Se procura como objetivos principales incentivar en el alumno el desarrollo de su pensamiento crítico y creativo y la utilización reflexiva de los contenidos vistos en clase; proveer vínculos con las prácticas profesionales de cada campo específico, como asimismo abrir instancias de interdisciplinariedad y estimular las habilidades y formas de procesamiento del conocimiento (deducción, inducción, clasificación, abstracción).

Palabras clave: arte - diseño - enseñanza - estética - escritura académica.

\section{Encuadre Académico del Proyecto}

Asignatura: Taller de Reflexión Artística I.

Proyecto pedagógico: Ensayos sobre la Imagen.

\section{Cuadernos del Centro de Estudios de} Diseño y Comunicación Nº 63

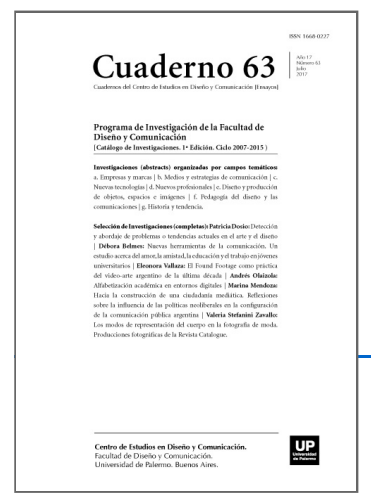

ISSN: 1668-0227

Programa de

Investigación de la

Facultad de Diseño y

Comunicación

Año XVII, Julio 2017, Buenos Aires,

descargar PDF

ver índice de la publicación

Ver todos los libros de la publicación

compartir en Facebook

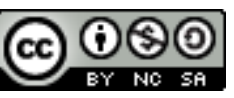

Esta obra está bajo una Licencia Creative Commons Atribución-NoComercialCompartirlgual 4.0 Internacional 
Área: Diseño Visual, con repercusiones en las áreas de Audiovisual, Modas, Comunicación y Creatividad.

Introducción

En este artículo se expone el planteo y desarrollo del proyecto áulico de educación superior denominado "Detección y abordaje de problemas o tendencias actuales en el arte y el diseño". La experiencia a través del dictado de la asignatura Taller de Reflexión Artística I ha conducido al desarrollo de la actual propuesta, ponderando la enseñanza de contenidos teóricos para alumnos provenientes de diversas carreras dentro del diseño (escenográfico, industrial, de indumentaria, gráfico, etc.) que en su mayoría se encuentran en la etapa inicial de formación. Cabe señalar que esta materia, de dictado cuatrimestral, se enmarca dentro de los estudios superiores de varias carreras que se dictan en la Facultad de Dise- ño y Comunicación de la Universidad de Palermo, como materia específica dentro del plan de estudios o como asignatura electiva, de acuerdo a la carrera de que se trate. Sus contenidos se refieren a las manifestaciones estéticas de los siglos XX y XXI y se articula y complementa con las otras materias del eje artístico: Taller de Reflexión Artística Il y Taller de Reflexión Artística III1 .

La propuesta contempla diferentes instancias a desarrollar por los alumnos a lo largo de la cursada, instancias conducentes a la realización de un ensayo académico como producción final. Este escrito ensayístico se encuadra dentro del proyecto pedagógico de la Facultad en el que participa la asignatura (Ensayos sobre la Imagen). El trabajo final que deben realizar los estudiantes radica, entonces, en expandir la investigación que deben efectuar durante el cuatrimestre. Esta investigación consiste en la captación, identificación de temas, cuestiones, líneas de trabajo o problemáticas dentro del área de diseño de cada estudiante (Diseño Industrial, Gráfico, Indumentaria, Historieta, etc.) y su puesta en relación con el tratamiento del mismo tema, cuestión, línea de trabajo o problemática desde el campo del arte, a partir de la obra de un artista latinoamericano emergente, de la joven generación o no consagrado. Se procura como objetivos principales incentivar en el alumno el desarrollo de su pensamiento crítico y creativo y la utilización reflexiva de los contenidos vistos en clase; proveer vínculos con las prácticas profesionales de cada campo, como asimismo abrir instancias de interdisciplinariedad y estimular las habilidades y formas de procesamiento del conocimiento (deducción, inducción, clasificación, abstracción).

A la hora de delinear el proyecto, con punto de partida en la planificación de base 2 , se han tenido en consideración determinados miramientos. Ante todo, la propuesta se enmarca en el rechazo de la linealidad de los desarrollos teóricos y de los reduccionismos, como podría serlo el plantear actividades como simples ejercicios de aplicación de la teoría o mera revisión de información almacenada. Además, se ha propiciado un diseño flexible y ajustable de acuerdo a los distintos momentos y a las características del alumnado, sus saberes previos e intereses. Cabe señalar la atención dada a la constante redefinición de objetivos, la interacción y los interrogantes que surgen en cada situación con los alumnos. Se trata de contribuir a una formación integral del futuro profesional en diseño que considera todas las dimensiones de la profesión, desde los procesos propios del diseño hasta los aportes de la psicología, la antropología, el arte, la sociología, la mercadotecnia, etc., aparte de la adquisición de habilidades y actitudes y, en definitiva, una preparación para el trabajo y para la vida.

En segundo lugar, se ha estimado lo relativo al propio campo disciplinar y su realidad académica: proporcionar a los alumnos el conocimiento de la historia del arte como disciplina científica, sus temas y problemas propios, haciendo hincapié en las producciones contemporáneas y sus enfoques teóricos. Del mismo modo, entablar las 
relaciones de la disciplina con otros campos, sus desarrollos universitarios y la investigación actual en el área; también la producción y lectura de imágenes, su historia y sus vínculos con las diversas culturas y sociedades.

\section{Tipología}

Se parte de la detección de un problema, tema o línea de trabajo dentro del campo del diseño, su análisis y puesta en relación con posibles acercamientos desarrollados en el ámbito del arte, para luego expandirlo a través de diversas instancias de producción. Se entiende por problema una serie de situaciones en un contexto dado, para cuyo examen el alumno requiere observar, investigar, reflexionar, juzgar bajo supervisión docente. En esta propuesta, los contenidos conceptuales del programa están estructurados en secuencias de aprendizaje orientadas a un fin concreto y teniendo en consideración los intereses del alumnado al que está dirigido, de manera que resulte factible establecer vínculos entre lo que previamente conocían y lo que se desea que aprendan para la consecución de un aprendizaje significativo.

\section{Necesidad que cubre}

Incentivo de las tareas de investigación y estímulo del pensamiento crítico y creativo, de fomento de un aprendizaje autónomo, involucrando cuestiones de actualidad y relativas a la profesión. Se trata de una propuesta de indagación sobre realidades profesionales existentes, relacionables con la temática del curso, cuya ejecución implica procesos de diagnóstico, exploración y evaluación.

\section{Funciones del docente}

La profesora responsable de la cátedra tuvo a su cargo el desarrollo de los dos bloques en que se dividieron las clases. Esto es, las lecciones magistrales y la tutoría (tanto presencial como virtual) centrada en el proyecto. En este sentido, el docente efectuó un seguimiento pormenorizado del trabajo de cada estudiante, definió las ayudas más adecuadas para cada uno, identificó sus dificultades y proporcionó, en los casos en que fue necesario, las herramientas metodológicas requeridas para reconducir su situación.

\section{Estudiantes}

Esta investigación se centró en la implementación del proyecto durante el primer cuatrimestre del ciclo lectivo 2011. La población del curso (turno tarde) fue numerosa y heterogénea en distintos aspectos; nucleó estudiantes de ambos sexos con predominio de mujeres (un $28 \%$ de varones sobre el total), algunos de los cuales procedentes de diferentes países latinoamericanos (aproximadamente un $30 \%$ de extranjeros), con variadas realidades laborales y formación académica de base. En cuanto a sus estudios superiores en desarrollo, éstos respondieron a diversos campos o áreas vinculadas al diseño. Concretamente, se trató de las carreras Diseño de Interiores, Diseño Gráfico, Diseño de Joyas, Licenciatura en Diseño de Espectáculos, Diseño Textil e Indumentaria y Licenciatura en Fotografía. Asimismo, en esta cursada se integraron estudiantes de la Licenciatura en Publicidad y de Producción de Modas.

Los alumnos partícipes de este proyecto áulico han sido los siguientes: Michella Braccalenti (Legajo: 61509), Rosalía Ingrid Cohen (Legajo: 64094), Guillermina Lafourcade (Legajo: 50370), Mónica M. Sosa Román (Legajo: 61034), Melisa Folatti (Legajo: 60081), María Laura Mognoni Dagnino (Legajo: 63373), Ailin Majeras (Legajo: 61852), José Guillermo Aquino Guevara (Legajo: 51285), Ivana Gabriela Castro Díaz (Legajo: 62259), Julián 
Federico Halbrich (Legajo: 65875), María de los Milagros Pascual (Legajo: 61689), Tania Mercedes Simbrón Segovia (Legajo: 44446), Manuela Sayago (Legajo: 60328), Felipe Esteban Abraham Arce (Legajo: 60633), Mauro Davide Bucher (Legajo: 59942), Gabriel Matías Ekboir (Legajo: 51032), Edgar Gabriel Espinoza (Legajo: 46271), Carlos Espinoza (Legajo: 61349), Analía Susana Garay (Legajo: 57794), Erika Hansen (Legajo: 62475), Gisella Amanda Leo Méndez (Legajo: 45489), Luoshen Lin (Legajo: 61826), Solange Antonella Magliano (Legajo: 62028), Camila Mendoza (Legajo: 61581), María Agustina Nieto (Legajo: 61688), Claudia Peschiera (Legajo: 63997), Luciana Ríos Stay (Legajo: 62356), María Eugenia Echeverría (Legajo: 62521).

Articulación vertical del proyecto. Descripción por etapas

Para la realización de este proyecto áulico se ha tenido en consideración inicialmente el tema general planteado por la Facultad de Diseño y Comunicación para el Programa de Producción Académica (Ensayos sobre la Imagen). Este tema estriba en la exploración de nuevas tendencias en el campo del arte y la creatividad. En este marco se define tendencia como "un mecanismo social que regula las elecciones de los sujetos. Se trata de un patrón de comportamiento determinado por cada sociedad y su época. La idea es que el estudiante capte acciones y aspectos subyacentes que puedan en un futuro convertirse en tendencias"3. Su objetivo principal reside en promover el acercamiento y la reflexión académica sobre obras y creativos contemporáneos latinoamericanos y la estimulación de la posibilidad de descubrir acciones y aspectos subyacentes que puedan convertirse en próximas tendencias. Se propone un enfoque metodológico que pondere el empleo de textos y fuentes de primera y segunda mano, la contextualización teórica, histórica y social. Es de relevancia que el alumno plantee sus propias reflexiones sobre el objeto de estudio, como premisa básica. Asimismo, son sugeridos distintos momentos de trabajo (como la búsqueda y análisis de fuentes, argumentación e intercambio de ideas, recapitulación)4 .

En articulación con el proyecto pedagógico brevemente descripto en el que participa la asignatura, la presente experiencia áulica contempló diferentes instancias de trabajo conducentes a la realización de un ensayo final por parte de los alumnos. Este ensayo de carácter académico estriba en la captación, identificación de temas, cuestiones, tendencias o problemáticas dentro del área del diseño de cada estudiante (Diseño Industrial, Gráfico, Indumentaria, Historieta, Publicidad o Fotografía) y su puesta en relación con el tratamiento del mismo tema, cuestión, tendencia o problemática desde la mirada del arte, a partir de la elección de un artista latinoamericano emergente.

La realización de esta actividad final se desarrolló en secuencias que se concretaron a partir del tercer trabajo práctico (TP3). Los dos primeros trabajos prácticos (TP1 y TP2) fueron de carácter introductorio, con el fin de que los estudiantes fueran adquiriendo las competencias básicas para el análisis conceptual y visual. En un caso (TP1) se trató de la reflexión sobre el concepto de arte como una noción culturalmente determinada y sus vínculos con el diseño. En otro (TP2), el examen visual de producciones impresionistas y postimpresionistas. Este proyecto áulico se desenvolvió en forma paralela al dictado de los contenidos del curso, destinándose parte de la clase a su construcción por etapas.

Planificación de la asignatura

La materia Reflexión Artística I se configura a partir de cinco grandes temas o módulos conceptuales. A continuación, se detallan estos módulos con agregado de las principales estrategias didácticas desplegadas en 
El paso de la concepción de la obra de arte como objeto cultural a objeto autónomo. El concepto de arte como noción culturalmente determinada. La magia: objetos y pinturas paleolíticas. Lo bello: arte griego. Idealismo y naturalismo en las distintas manifestaciones del arte medieval. Renacimiento: el humanismo y la creación de la perspectiva. Barroco: la Contrarreforma y la inclusión del momento dramático en la obra. Acercamientos teóricos y perspectivas historiográficas sobre la producción artística y el diseño.

Actividades: Presentación de la asignatura. Coloquio. Exposición teórica. Análisis de obras representativas de los períodos estudiados: la representación de la figura humana a través de los períodos mencionados. Trabajo en grupos para debatir los conceptos presentados

II. Hacia las vanguardias. Los movimientos del siglo XIX

a)

Introducción a la problemática de las vanguardias: las corrientes del siglo XIX. Lo clásico y lo romántico: objetividad y norma frente a expresión y subjetividad. El Historicismo. Contexto histórico. Antecedentes del movimiento Impresionista: Ios paisajistas de la Escuela de Barbizon, El Realismo. El primer rompimiento del canon clásico: Edouard Manet. Actividades: Exposición teórica. Análisis de obras representativas de los períodos estudiados. Trabajo en equipo de análisis e interpretación de los conceptos presentados.

b)

Impresionismo y Divisionismo: El nacimiento de las megalópolis y el arte urbano. El avance científico y las nuevas tecnologías: su incidencia en la representación de la forma, la luz y la percepción cromática. La obra de Claude Monet, Pierre Renoir, Edgar Degas. El Divisionismo: concepción cientificista de la pintura. La obra de Georges Seurat y Signac. Actividades: Exposición teórica. Análisis de las características de los movimientos a través del análisis de obras de los artistas estudiados.

c)

Arte y Diseño: La función social del arte en las nuevas ciudades cosmopolitas. La producción en serie como puesta en crisis de la idea de original en la obra de arte. Los diseños publicitarios: el cartel de fines de siglo XIX. Las nuevas técnicas de impresión y su influencia en los sistemas de representación. Arte documental.

Actividades: Exposición teórica. La nueva ciudad de París analizada mediante planos, grabados y fotografías anteriores y posteriores a las reformas del barón Hausmann. Análisis de imágenes publicitarias. El concepto de modernidad como experiencia vital (M. Berman).

d)

Simbolismo: Los temas literarios y la remisión al arte primitivo. El mito de evasión; su relación con la literatura de Charles Baudelaire y Edgar Allan Poe. La influencia de las grandes urbes en los cambios de la mirada. La obra 
de Paul Gauguin como antecedente del Fauvismo. La obra de Vincent Van Gogh como antecedente del Expresionismo. La obra de Paul Cézanne como punto de partida de todo el arte moderno.

Actividades: Exposición teórica. Análisis de obras de los artistas estudiados. Lectura de fragmentos literarios.

e)

Art Nouveau: Antecedentes de la concepción totalizadora del diseño: el Movimiento Arts and Crafts; el papel de John Ruskin y William Morris ante las nuevas tecnologías. La concepción de diseño en textiles, indumentaria, objetos industriales, obras de arquitectura y gráficas. Análisis de sus manifestaciones en distintos centros europeos: Escocia, Bélgica, Austria, Alemania y las diferencias formales en obras de Charles Mackintosh, Victor Horta, Otto Wagner, Joseph Hoffmann y Herman Obrist. Los Estados Unidos y la obra de Louis Sullivan. La obra gráfica de Alphonse Mucha, Audrey Beardsley, Gustav Klimt. El nacimiento del cine y su influencia en el diseño visual.

Actividades: Exposición teórica. Análisis de reproducciones de obras de los artistas estudiados. Reflexión acerca de las relaciones entre cambio formal y contenido expresivo. Comparación entre obras de producción única y seriada.

III. Las vanguardias históricas. El retorno al orden

a)

Fauvismo y Expresionismo: Los fauves y la herencia de la obra de Gauguin. El primitivismo como fuerza impersonal. Destrucción de la subjetividad. Uso del color como plano expresivo. La obra de Henri Matisse. El Expresionismo alemán y austríaco. La herencia de Van Gogh. El uso de las formas como expresión de la subjetividad. El grabado. Die Brücke y Blaue Reiter en Alemania. Egon Schiele y Oskar Kokoschka en Austria.

Actividades: Exposición teórica. Análisis de obras de los artistas estudiados. Reflexión acerca del carácter global del movimiento en el campo del arte y el diseño.

b)

Cubismo y Futurismo: Orígenes y planteos históricos del Movimiento Cubista. La descomposición del modo de representación renacentista: el cuestionamiento de la relación entre el modelo real y la visión, el cuestionamiento de la idea de belleza y la categoría de lo feo; el empleo de materiales no elaborados plásticamente, la técnica del collage. Tipos de cubismo. La obra de Georges Braque y Pablo Picasso. Futurismo: su propuesta plástica, la introducción de la idea de representación temporal. Los manifiestos y la actividad artístico-política. Relación con la literatura de Mallarmé y los caligramas de Guillaume Apollinaire.

Actividades: Exposición teórica. Análisis de obras de los artistas estudiados. Reflexión acerca de la influencia del movimiento expresionista en el diseño. Lectura de manifiestos.

c) 
Abstracción Geométrica, Constructivismo: Suprematismo y constructivismo como corrientes ideológicamente antitéticas en la Unión Soviética a principios del siglo XX. El diseño y sus propuestas ante las nuevas políticas sociales. La obra gráfica de Maletvich y Talin. El cine soviético y su concepción de montaje visual. Neoplasticismo: comienzo del arte concreto. La obra gráfica de Theo van Doesburg. Su concepción de diseño total. La obra de Piet Mondrian.

Actividades: Exposición teórica. Análisis de obras de los artistas estudiados. Lectura de manifiestos artísticos y análisis de su materialización en las obras. Proyección de fragmentos fílmicos (El Acorazado Potemkim).

d)

La Bauhaus: Antecedentes históricos. El papel ideológico del Deutsche Werkbund y la obra de Peter Behrens. La Bauhaus como origen del concepto de diseño contemporáneo y su relación con las artes plásticas. Los programas pedagógicos y la enseñanza en talleres. Las etapas de Walter Gropius, Hannes Mayer y Ludwig Mies van der Rohe. La influencia de Paul Klee, Wassily Kandinsky, Johannes Itten. La obra gráfica de Herbert Bayer y Lászlo Moholy-Nagy. El Art Déco y su influencia en el diseño de objetos.

Actividades: Exposición teórica. Análisis visual de obras de la Bauhaus y reflexión acerca de la función social del diseñador en los contextos históricos.

e)

Corrientes irracionalistas: Dadá y Surrealismo: Dadaísmo, anarquismo y la ruptura de categorías tradicionales del arte. La irrupción del material en bruto, el fotomontaje, lo lúdico y el azar como pérdida del control racional sobre los contenidos temáticos de la obra. La obra de John Heartfield y Man Ray. Marcel Duchamp como origen del arte de posguerra. Surrealismo: influencia de los mitos literarios y el psicoanálisis en la búsqueda de imágenes provenientes del inconsciente. La pintura de Salvador Dalí y Marc Chagall. La pintura flamenca y la retórica visual: la obra de René Magritte. El automatismo: la obra de Marx Ernst y Joan Miró.

Actividades: Exposición teórica. Análisis visual. Proyección de fragmentos fílmicos (Un perro andaluz). Debate sobre la noción de "objetos de ansiedad" de Harold Rosenberg.

IV. Las postvanguardias

a)

Arte de post-guerra. Informalismo y Pop Art: Expresionismo Abstracto, origen en la obra de Wassily Kandinsky.

El Action Painting y la actitud expresionista: pintura sígnica y gestual. La obra de Jackson Pollock. La desintegración del material; su antecedente en el Dadaísmo. El arte Informalista europeo. La inclusión del espectador como parte activa de la obra: Land art. El Cinetismo y el Op Art. El arte Pop como reacción contra la abstracción. La consideración del consumismo como tema. La generación beat. La importancia de los medios de comunicación en la imposición de imágenes de arte. Los antecedentes en la obra de Robert Rauschenberg, Jasper Johns y Richard Hamilton. La obra de Andy Warhol y su impacto en la gráfica. Actividades: Exposición teórica. Análisis de obras de los artistas estudiados, reflexionando acerca de la función de la obra de arte como crítica histórico-social. 
Arte latinoamericano: Desarrollo de las corrientes de vanguardia europeas en Latinoamérica. Muralismo mexicano y su influencia en el resto de América Latina. El Río de la Plata y el arte de vanguardia: la obra de Torres García en Uruguay. Las corrientes surrealistas: la obra de Roberto Matta, Wifredo Lam, Raquel Forner y Xul Solar. El cubismo: Emilio Pettoruti. Los movimientos abstracto-geométricos: Tomás Maldonado, Gyula Kosice. La nueva figuración. La experiencia pop del Instituto Di Tella y la experimentación sobre nuevas formas artísticas.

Actividades: Exposición teórica. Análisis de obras de los movimientos estudiados y comparación de las distintas características según el contexto geográfico.

V. La producción artística de las últimas décadas. Arte contemporáneo.

Las artes del cuerpo: performance, happenings, body art, enviroments. La inclusión del espectador en la obra. Las nuevas tendencias artísticas y la herencia de la Postmodernidad. Nuevas formas de expresión: video-arte, instalaciones, graffitti. El arte conceptual. La experiencia argentina. Relación actual arte-diseño.

Actividades: Exposición teórica. Análisis de obras de los movimientos estudiados. Discusión sobre el concepto de arte relacional (Nicolás Bourriaud) y de estética de la emergencia de Reinaldo Ladagga.

El tramo final de la cursada se estructura en tres momentos: el primero apunta a la revisión de contenidos. Es también la última oportunidad de recuperar trabajos o de entregar tareas adeudadas. El segundo momento es el cierre de notas de cursada. Los alumnos entregan sus carpetas o portafolios de cursada. Tiene lugar el Cierre de Actas de Cursado y el informe de notas a los estudiantes. El último momento se centra en las consultas y correcciones del trabajo práctico final, el ensayo.

Los objetivos generales de la materia pretenden que los estudiantes puedan conocer y reconocer las manifestaciones estéticas del siglo XX y XXI; integrar las manifestaciones sociales, artes visuales y corrientes de diseño; desarrollar la capacidad crítica y el criterio estético como forma de ampliar y enriquecer las posibilidades expresivas en el diseño; valorar situaciones contemporáneas desde una perspectiva histórica; y ahondar en la reflexión y el análisis crítico de los lenguajes visuales actuales.

Dentro de los objetivos específicos se intenta que loa alumnos estén en condiciones de complementar los aspectos morfológicos, perceptivos y conceptuales adquiridos en otras asignaturas de la carrera a través del análisis de ejemplos de los movimientos artísticos del siglo XX y XXI; interpretar los cambios en la visualidad actual como producto de la problemática artística planteada por las vanguardias históricas y las posvanguardias del siglo XX; comprender el proceso de autonomización de las disciplinas del diseño desde las creaciones de nuevos lenguajes visuales desarrollados en el campo artístico; y aplicar estos conceptos en producciones propias.

Detalle de las actividades organizadas bajo la forma de trabajos prácticos

Las siguientes actividades o trabajos prácticos constituyeron las diversas instancias a través de las cuales los alumnos fueron construyendo su proyecto en forma secuenciada. Los dos primeros trabajos (A) revestían un 
carácter introductorio, mientras que los trabajos siguientes (B) eran específicos del proyecto y se organizaron en cuatro etapas de elaboración.

\section{A. Trabajos Prácticos Introductorios:}

TP1. "Arte y Diseño" Consigna: El alumno debe seleccionar reproducciones de una obra plástica y de un objeto de diseño y construir una definición propia de los conceptos de "arte" y de "diseño" a partir de la observación de las mismas bajo la forma de un mapa conceptual, incluyendo las imágenes elegidas.

Bibliografía obligatoria: -“Acerca del concepto de arte” Material de Cátedra.

- López Anaya, Jorge, “El ocaso de la obra maestra”, La Nación, 28/01/2007.

Bibliografía optativa: Gombrich, Ernst, "Introducción. El arte y los artistas", en: Historia del Arte, Sudamericana, Buenos Aires, 1999.

Forma de Presentación: Hojas A3, carátula según normas de la Facultad.

Fecha de entrega: Clase segunda. TP2. "Artes visuales: análisis de obras artísticas" Consigna: El alumno debe seleccionar una reproducción de una obra perteneciente a pintores impresionistas o postimpresionistas y analizarla en base a las consignas de la Guía de análisis. Desarrollar un informe de mínimo dos páginas en las que se incluyan las imá- genes seleccionadas.

Forma de Presentación: Hojas A4, numeradas, carátula según normas de la Facultad. Fecha de entrega: Clase cuarta.

B. Trabajos Prácticos Específicos (involucrados directamente con el proyecto):

Primera etapa: Consiste en introducir al alumno en el género ensayo académico, cuya forma debe adoptar para presentar su pesquisa. En este sentido, se pretende encauzar al alumno en un acercamiento al dominio de las pautas principales del género. La segunda instancia es la identificación del tema, cuestión, línea de trabajo o problemática a través de una micro-investigación supervisada por el docente. Por ello, se ha previsto su realización en clase, empleando los recursos provistos por la Facultad (Sala de Informática y Biblioteca). Se trata del TP3 subdividido en tres partes: TP3. "Diseño: ensayo sobre el diseño actual” Consigna: Primera parte: ¿Qué es un ensayo? Sintetizar sus principales lineamientos bajo la forma de un cuadro sinóptico en base al apunte Sobre el ensayo.

Segunda parte: identificar dentro del diseño actual alguna problemática, tendencia, línea de trabajo y desarrollarla mediante una micro-investigación. Puede orientarse con la guía Líneas posibles y el artículo "Diseño revisitado".

Tercera parte: presentar la micro-investigación bajo la forma de un ensayo académico, teniendo en consideración lo efectuado en la Primera parte.

Forma de Presentación: Hojas A4, rotulado según normas de la Facultad. 
Fecha de entrega escrita y oral: Clase sexta.

Segunda etapa: Se focaliza en la elección de un artista o diseñador, siguiendo los lineamientos propuestos en el TP4.

TP4. "Artes visuales: nuevas corrientes" Consigna: Elegir un artista latinoamericano (joven generación o no consagrado) y exponer sintéticamente teniendo en cuenta: a) corriente a la que pertenece; referentes; b) temática de trabajo; c) análisis de alguna de sus obras; análisis crítico de su producción o conjunto de obras; d) sus vínculos con la problemática anterior (del TP3).

El desarrollo de los dos primeros puntos ( $\mathrm{a}$ y $\mathrm{b}$ ) se basa en una entrevista con el artista elegido (obligatorio). Usar la Guía entrevistas. Se ofrece además un listado de artistas posibles para trabajar.

Forma de Presentación: Hojas A4, numeradas, carátula según normas de la Facultad.

Fecha de entrega: Clase octava.

Tercera etapa: Esta instancia promueve una expansión del punto d) del TP4, consistente en una primera aproximación al planteo de vínculos conceptuales entre el tema elegido y la producción del artista seleccionado (o su recorte: un conjunto de obras, una obra).

Esta etapa se concreta mediante el diseño de un proyecto de montaje de una exhibición de la producción del artista elegido, teniendo como concepto de base una elaboración de las relaciones planteadas. El trabajo práctico que corresponde a esta etapa es el siguiente: TP5. "Artes visuales y Diseño: Nuevas Corrientes" Consigna: Se propone proyectar el montaje de una exposición de la obra del artista elegido para el trabajo anterior (TP4). Se trata de un proyecto (no de su concreción efectiva). Este proyecto se subdivide en dos instancias que involucran distintos tipos de tareas:

a) Tareas de diseñador. Los estudiantes, como diseñadores -según el área a la que pertenecen-, deben confeccionar para dicha exhibición, el diseño o boceto de (opciones, a elegir una): - catálogo, - objeto de iluminación, - ambientación, - merchandising, o - indumentaria.

También deben tener en consideración que el espacio donde se realizará la muestra es el patio de la sede Jean Jaurés de la Universidad.

b) Tareas de curador. Aparte del trabajo como diseñadores, en esta tarea los alumnos se desempeñan como "curadores". En este sentido, deben ocuparse de: - la elección de las obras a exhibir, - la Organización Temática de las mismas, - y el Recorrido Posible para el espectador (que deben fundamentar por escrito).

Tanto la Organización Temática como el Recorrido Posible tienen que conectarse con el tema del TP3.

Forma de Presentación: Hojas A4 y soporte A3, rotulado según normas de la Facultad.

Medios expresivos libres. El trabajo debe constar de: -(en A4). Introducción (artista elegido. Obras a exponer. Organización temática de las mismas; recorrido propuesto para el espectador y su fundamentación ¿por qué?). 
Croquis o plano de la muestra (con la ubicación espacial de las obras).

-(en A3). Boceto de la producción elegida (punto a).

Fecha de entrega escrita y oral: Clase décimo primera.

Cuarta etapa: Para el Trabajo Final el alumno deberá profundizar los siguientes aspectos: el tema elegido y su puesta en tensión con el enfoque del mismo tema dado por el artista seleccionado a través del recorte de su obra que el alumno haya instrumentado. Para tales fines, debe introducir como complemento para su reflexión personal final diversos tipos de fuentes (entrevistas al artista, público, Expertos (críticos, galeristas, coleccionistas, profesores), otros artistas; comentarios críticos publicados en la prensa y revistas especializadas, bibliografía general y específica). Su presentación responde a las pautas básicas del género ensayo académico, ya tratadas en clase, con consignas y normas explicitadas en la guía correspondiente.

\section{Metodología de trabajo}

Para encauzar este proyecto áulico se ha optado por una metodología activa y cualitativa acorde con un enfoque didáctico centrado en el estudiante, de base constructivista, que se adecue a los objetivos generales y específicos de la asignatura. Las características del trabajo final lo aproximan al método conocido como aprendizaje orientado a proyectos. Cada actividad o tarea pondera su etapa de preparación, realización y revisión apuntando a un aprendizaje autónomo y significativo, lo cual supone también una actividad colaborativa en cuanto a recursos, consulta e intercambio con profesores, tutores, compañeros. Tanto la realización del ensayo final como la de los trabajos parciales fueron estadios de elaboración individual, con presentaciones escritas y orales. Sin embargo, estos momentos se articularon con el recurso a técnicas de dinámica grupal, como la generación de discusión guiada y debate, brainstorming, análisis de textos, estudio de casos, de acuerdo con las metas que se buscaron alcanzar en cada momento (obtención de información, especificación del tema, incentivo de la creatividad, intercambio de experiencias). Se trata de una metodología que estudia las cuestiones educativas en el propio contexto de clase y que pretende intervenir en el mismo con el fin de provocar modificaciones favorables para los aprendizajes. Este tipo de intervenciones permite que los resultados obtenidos puedan emplearse para transformar aspectos de la propia propuesta o de sus aplicaciones posteriores5.

Implementación del proyecto. Descripción de la experiencia. Estructura del curso

Teniendo en cuenta la duración de cada clase semanal (tres horas reloj), la asignatura se estructuró en dos bloques orientados a la consecución del proyecto6. El primero de los bloques correspondió a los temas teóricos a tratar en las lecciones magistrales, de configuración predominantemente progresiva, lineal, con el auxilio de diversos recursos didácticos y actividades (ya señalados en la planificación). En la primera clase de presentación fueron anunciados los saberes que se desplegaron a lo largo de la cursada (dentro de este primer bloque). Estos contenidos conceptuales específicos de la materia se hallaban secuenciados tratando en lo posible de tener en cuenta las necesidades del alumno a la hora de realizar su proyecto. Es decir, dado que las últimas clases apuntaban a la producción artística actual (coherente con el período en el que se situaban los proyectos del alumnado), con respecto a los temas de las clases previas (por ejemplo, las vanguardias históricas) se buscó establecer vinculaciones y puentes con las prácticas estéticas del presente. Además, estos 
temas encontraban instancias de elaboración parcial en los trabajos prácticos y en las actividades a desarrollar en clase, comunes a toda la población del curso. Los trabajos prácticos parciales permitieron estructurar las tareas de aprendizaje y sostener una evaluación continuada que se convirtiera en un hecho formativo y no únicamente en un trabajo con repercusión en las calificaciones finales.

El segundo bloque consistió en la tutoría basada en una organización en red de intercambios y centrada en el tratamiento específico de los proyectos de los alumnos. Esta tutoría a cargo del docente revistió una modalidad presencial a través de las clases y el espacio brindado por los Módulos de Atención y Producción (horas MAP), como así también virtual7 . La importancia de la tutoría reside en que recupera la noción de andamiaje o proceso de interacción entre el aprendiente y su tutor. El seguimiento de estos trabajos fue muy personalizado, al ser tareas individuales y encuadradas dentro de los distintos ámbitos del diseño. En esta dirección, se emplearon fichas para apuntar los trabajos y su evolución, variaciones y pasos a seguir. En la ficha modelo para cada alumno se detallaron estos ítems y su estado (MB: muy bueno; B: bueno; R: regular; I: incompleto) que facilitó el sondeo, corrección y reconducción del proceso de trabajo8 .

Asimismo, se han confeccionado diferentes materiales para la práctica de las distintas competencias que debieron llevar a cabo los estudiantes (desde la realización de una entrevista o un mapa conceptual hasta las maneras de citar, elaborar un ensayo y la forma de presentarlo)9 .

Las clases que componen este segundo bloque correspondiente a la tutoría se han organizado según el siguiente esquema: en la primera clase se plantearon y describieron las actividades y trabajos a los alumnos. Se presentó el Block de Materiales de Cátedra que incluyó la planificación, bibliografía, detalle de trabajos prácticos parciales, guías y artículos complementarios, copia de declaración jurada a adjuntar en la entrega final, criterios de evaluación e indicaciones sobre la organización formal y formato de entrega de actividades y ensayo final, además de materiales de lectura.

Al tratarse de una materia nueva, contenidos nuevos y una propuesta de trabajo asimismo novedosa, son de suma relevancia las clases iniciales, que ostentan como objetivo principal encaminar al estudiante hacia la definición del tema punto de partida, sobre el cual organizará todo su trabajo posterior. En este sentido, en la segunda clase se proporcionó un panorama de las posibles líneas actuales de debate en las diversas áreas del diseño y el arte a partir de las cuales se detectan tendencias, temas o problemas factibles de someter a estudio y reflexión. Entre ellos, se sugirieron como lineamientos generales la recuperación de las culturas autóctonas, las prácticas de reciclado, el cuidado del medio ambiente, la reinterpretación de modelos pasados, la incorporación de las nuevas tecnologías en la creación estética, estereotipos e imaginario colectivo. Se pretendió que el alumno interactuara con eventos y problemas del mundo contemporáneo a nivel local e internacional. Además, se les proporcionaron lecturas, sitios en Internet de información válida, tanto de arte como de diseño, técnicas de trabajo de campo con la finalidad de que comenzaran a tomar contacto con la actualidad de sus áreas disciplinares y lugares de rastreo de documentación o información legítima y vigente. Cabe señalar que esta información fue siendo aportada en forma progresiva a lo largo de varias clases con la finalidad de que fuera incorporada en forma gradual y efectiva, evitando "abrumar" al estudiante con un exceso de datos y actividades.

En general los alumnos, aparte de sus saberes de mundo o enciclopédicos y experiencias diarias, arriban al curso con inquietudes o intereses definidos. Estas inquietudes, que han podido surgir en otros ámbitos 
(asignaturas académicas, talleres, cursos, espacios laborales y profesionales), se tornan factibles de ser reconfiguradas con el fin de ser tratadas como tendencia o problema; en otras palabras, pueden ser profundizadas y adaptadas dentro de los límites del proyecto propuesto. Por otro lado, el partir de la detección de una tendencia o la formulación de un problema orienta el proceso de aprendizaje y enfatiza la generación de interrogantes; asimismo, al contextualizar esa tendencia o problema, se favorece la motivación y comprensión del alumno sobre los contenidos conceptuales. Se trata de una variante del aprendizaje autodirigido o, en la literatura anglosajona, el selfdirected learning10, pues se pondera un aprender conducido por el propio estudiante bajo la supervisión del docente.

En la siguiente fase se le solicitó al alumno la presentación de un boceto del tema elegido y su exposición oral frente al grupo y al docente. En el encuentro posterior, se llevó a cabo una micro-investigación en la Biblioteca de la Facultad de Diseño y Comunicación con el objetivo de rastrear material bibliográfico y hemerográfico. Es de subrayar que, como primera aproximación, esta instancia facilitó al alumno el cotejo del tema seleccionado con textos que brindan conexiones o marcos teóricos, incentivando y puliendo su tarea. La aspiración en esta fase fue justamente que los alumnos comenzaran a parangonar sistemas empíricos con sistemas teóricos de información; las experiencias y los lenguajes cotidianos con lo académico y lo conceptual.

Las clases sucesivas se dividieron en tres secciones. La primera se centró en el armado del proyecto de cada estudiante. Una vez bosquejado el tema dentro del área del diseño de cada alumno y concluida la primera fase de relevamiento o micro-investigación, se aconsejó la revisión del material informativo y su articulación a la luz de dos interrogantes que se constituyen en centrales en toda investigación: qué y cómo. La primera pregunta conduce a aquello que se está indagando y lo vincula con los saberes conceptuales, mientras que la segunda hace referencia al modo en que va a desarrollarse la indagación; atañe también a las opciones metodológicas y técnicas de exploración.

La segunda sección tuvo como eje el polo artístico con la elección del creativo latinoamericano emergente. Para la elección del mismo se propuso un listado de nombres opcionales, sitios de Internet fiables donde los estudiantes pudieran observar las obras, técnicas, orientaciones y opiniones de diversos artistas noveles. El discurso visual del artista ofrece un horizonte posible para encauzar una perspectiva desde el arte del tema en cuestión. Respecto a la realización de entrevistas al artista, ante la emergencia de ciertos imponderables (como la imposibilidad de entrevistarlo personalmente), se sugirieron caminos alternativos (entrevistas por e-mail, telefónicas, Chat, consultas a colegas, críticos, galeristas, profesores o público en general). También, de acuerdo a la tónica del trabajo, se indicó la opción por creativos vinculados más estrechamente con el diseño. En esta instancia, se subrayó la importancia del empleo de fuentes de primera mano que permiten al alumno construir su mirada crítica.

La tercera sección de clases se orientó hacia la puesta en tensión entre la propuesta artística y el tema, ambos elegidos por cada estudiante: los aportes del recurso a la óptica de ese artista en particular, perspectivas de análisis abiertas, reflexiones personales. Luego, se ponderó su organización formal bajo la forma de un ensayo y la elaboración de ideas finales. Para ello, previamente los alumnos se adentraron en la configuración básica de un ensayo académico como género específico, sus objetivos, pautas, rasgos propios.

Paralelamente al desarrollo de las clases, fue constante la comunicación con el docente a través de informes periódicos; se implementaron mini-presentaciones orales de los avances por parte de los estudiantes, 
generando la confrontación y debate, trabajos en grupos sobre lecturas puntuales, intercambio de opiniones (lluvia de ideas) sobre las exposiciones de los propios alumnos, resolución de casos, análisis visuales y textuales. Asimismo se estableció un momento a mitad de la cursada similar a un parcial "a libro abierto": del mismo modo que un parcial, de carácter obligatorio y con calificación numérica, los alumnos debieron prepararse y traer al curso los materiales de su pesquisa (borradores, documentación, textos, imágenes y artículos rastreados hasta el momento) para confeccionar y entregar un boceto de sus ensayos. El objetivo de esta actividad apuntó menos a la obtención de una calificación puntual, que a definir la primera fase de la escritura, la planificación de lo escrito, el recorte del tema, revisiones (qué datos son necesarios y cuáles son prescindibles), autoevaluación de lo efectuado y, al mismo tiempo, espacio de motivación para los alumnos hacia el desarrollo de la autonomía personal, el compromiso y la responsabilidad. Otra instancia fue la exposición y análisis de un ejemplo de ensayo elaborado por la Cátedra mediante materiales fundamentalmente visuales. La función de este recurso fue la presentación a los alumnos de un modelo básico que les permitiera clarificar y reorientar, según el caso, sus propios trabajos.

Los últimos encuentros se destinaron a encaminar a los alumnos en el fortalecimiento de los vínculos establecidos entre la mirada desde el arte sobre el tema seleccionado en el ámbito del diseño; el análisis de las entrevistas y la reflexión sobre lo investigado. En esta etapa se puso el acento en la importancia del hecho de que los estudiantes, por un lado, percibieran a sus propios trabajos como una totalidad integrada y no como una reunión de partes o fragmentos acerca de una cuestión determinada; y, por otro lado, que no descuidaran el cuño ensayístico del mismo, a fin de no caer en presentaciones monográficas o biográficas.

\section{Propuesta de Evaluación}

Es importante señalar que en el marco de esta experiencia áulica se previó una evaluación del trabajo de los alumnos y de la propia experiencia. La evaluación del trabajo de cada estudiante se basa en criterios referentes a las diversas instancias de trabajo, que han sido explicitados desde el inicio del curso, junto con la planificación e introducción a la asignatura y proyecto.

En líneas generales, se ponderaron distintos grados de exigencia que denotan esfuerzo e interés creciente, conducentes a la formación del pensamiento propio y la comprensión de las ideas ajenas: - Cumplimiento de los objetivos mínimos.

- Redacción clara y entendible.

- Expansiones o ampliaciones de las actividades.

- Consulta y atención a las correcciones y sugerencias.

- Aportaciones originales.

- Internalización de los aprendizajes.

- Instancia auto evaluativa. En concreto, fueron considerados tanto los trabajos prácticos introductorios y específicos como el desarrollo del ensayo final; la participación en las clases y tareas grupales como su nivel de compromiso y responsabilidad. Los criterios de evaluación que se aplicaron a cada entrega de trabajos prácticos 
consistieron en: Para las producciones escritas: - Organización de la producción escrita (delimitación de la introducción, desarrollo y cierre, según el tipo de producción solicitada).

- Indicación y ordenación de la Bibliografía (libros impresos y textos digitales según normas de la Facultad).

- Lectura y apropiación del material de las clases y textos.

- Claridad conceptual y planteo de relaciones.

- Profundización temática.

- Resolución original de problemas o resolución que dé cuenta de un sistema de aplicación; empleo de distintos niveles de análisis.

- Manejo del vocabulario específico.

- Respeto por las normas de presentación, prolijidad, ortografía y puntualidad en las entregas. Para las presentaciones orales: - Manejo del vocabulario específico.

- Demostrar lectura y apropiación del material de las clases y textos.

- Claridad en la exposición y en el planteo de relaciones.

- Presentación correcta y apropiada del material gráfico o digital. En todos los casos durante la cursada se reconoció el particular crecimiento del estudiante, su esfuerzo y dedicación; esto es, aspectos procedimentales y actitudinales.

Se trata de una evaluación formativa de carácter continuo; para este fin se confeccionaron fichas de seguimiento (ya descriptas)11 y fichas de los primeros avances. Asimismo, como ya se ha mencionado con anterioridad, se planteó un momento de evaluación donde la consigna fue dar cuenta de lo efectuado hasta la fecha, cumpliendo con un papel de regulación de los aprendizajes. En efecto, aparte de subrayar lo relativo a la responsabilidad e implicación del alumno -por la obligatoriedad del ejercicio- esta instancia permitió resaltar los logros alcanzados como aquello pendiente, y no perder la dirección de la tarea final hacia la modalidad ensayística.

\section{Encuadre Teórico}

La propuesta áulica desplegada apuntó fundamentalmente a favorecer los procesos de construcción del conocimiento mediante el empleo de distintas entradas al saber: modos narrativos, razonamientos deductivos, apreciaciones estéticas, experienciales, aspectos sensoriales y personales, o relacionados con aspectos de aplicación12. Mediante este proyecto de actividades escalonadas con eje en el tema punto de partida (descripto en la segunda parte del TP3), se postuló un abordaje que emerge de la investigación cognitiva y constructivista en educación.

En este sentido, se buscó, por un lado, generar una atmósfera que estimulara a los estudiantes a pensar por sí mismos y que pudieran apoyarse en los esfuerzos a realizar en cada instancia. Por otro lado, a través del 
recurso al oficio (curador, diseñador) se intentó mostrar a los alumnos los procesos del pensar propios de las actuaciones expertas, al generar puertas de entrada a problemas y prácticas propias del campo profesional. Además, esta apelación se fundamenta en su potencialidad de atravesar los distintos niveles de saber característicos de la enseñanza universitaria: nivel conceptual, de resolución de problemas, epistémico e indagación13.

Es importante señalar que el presente proyecto áulico, en lo esencial, ya se había comenzado a implementar a partir del primer cuatrimestre del año pasado, dando resultados satisfactorios con respecto a: - Reflexión e investigación sobre el propio campo disciplinar.

- Reflexión e investigación de la producción artística contemporánea y del campo artístico actual.

- Evitar situaciones de copia o plagio, debido a que el núcleo fuerte del trabajo lo constituye el establecimiento de vínculos, tensiones entre el área del diseño y del arte y sus diversos enfoques de un misma o similar problemática, tendencia o cuestión de actualidad.

- Producción creativa a partir de un fundamento conceptual mediante el trabajo de proyectar una exposición.

- Rendición de examen final en la fecha inmediatamente posterior a la cursada de un importante porcentaje de estudiantes (a diferencia de los cursos previos a la implementación de este proyecto). En esta última edición, el proyecto modificó algunos aspectos fundamentalmente debido a las características específicas del grupo de estudiantes. Las demás variables (como infraestructura, tiempo o cantidad de clases, condiciones del entorno, recursos, materiales, propósitos institucionales, disponibilidad de los artistas o diseñadores para ser entrevistados) no presentaron grandes cambios ni implicaron alteraciones considerables al proyecto en sí. En esta dirección, los rasgos del grupo de alumnos involucra a: - Edad, año de estudios y área académica.

- Capacidades, experiencias, habilidades y saberes previos.

- Número de estudiantes que integran el grupo. Debido a que esta propuesta pedagógica propició capacidades de autorregulación en el aprender, interesa hacer una breve referencia a los estilos de aprendizaje y los estilos cognitivos. Si bien existen diversas interpretaciones sobre la cuestión y una amplia bibliografía, la literatura especializada diferencia entre ambos constructos14. Así, los estilos de aprendizaje remiten a las preferencias de los sujetos con respecto a las maneras de aprender que consideran más apropiadas para sí mismos. Los estilos cognitivos, en cambio, refieren al modo habitual de acercarse a la información, resolver problemas, o a cómo se lleva a cabo una actividad independientemente de su contenido. Además, se hallan vinculados al aprendizaje autorregulado y guarda correspondencias con la obtención de rendimientos fructíferos. La autorregulación consiste en la capacidad que un individuo adquiere para promover su propio proceso de aprender mediante una serie de estrategias motivacionales, cognitivas y metacognitivas. Se trata de la posibilidad de que el estudiante sea capaz de formularse metas, planificar actividades para la consecución de tales metas, controlar los tiempos, evaluarse a sí mismo, valorar sus resultados. De este modo, el sujeto construye conocimiento significativo y a la vez "conlleva un autoconocimiento respecto a las formas individuales más eficaces para utilizar o aplicar lo aprendido"15. 
Esta capacidad puede aprenderse y desarrollarse; los estilos de aprendizaje pueden cambiar. Por ello es de importancia que las experiencias áulicas adopten perspectivas donde el papel activo de los estudiantes en su proceso de aprendizaje sea contemplado como central, mientras que la figura del profesor actúe como tutor activo ofreciendo apoyos al estudiante en su proceso de aprender. Desde esta óptica, los alumnos partícipes del proyecto plantearon objetivos a partir de la elección de una tendencia o cuestión determinada, organizaron sus tiempos, efectuaron revisiones diversas, autoevaluaciones y redefinieron o cambiaron estrategias, bajo la orientación y soporte del docente16.

Resultados obtenidos

El trabajo de los alumnos

Para facilitar la percepción de los resultados obtenidos se ha optado por diferenciarlos según se trate de los trabajos prácticos parciales o de la organización del ensayo conclusivo. Asimismo, se ha optado por mencionar las cuestiones a grandes rasgos más notables en cuanto a falencias o puntos débiles y logros.

a) Trabajos prácticos introductorios y específicos

Los trabajos iniciales (TP1 y TP2) no han presentado inconvenientes de realización y comprensión de consignas entre los alumnos y, en general, han sido entregados en fecha y forma. En cambio, con respecto al tercer trabajo práctico específico (TP3) algunas presentaciones adolecieron de problemas a la hora de la aplicación conceptual. En efecto, si bien desarrollaron en forma correcta la lectura del texto sobre qué es un ensayo y lograron confeccionar un mapa conceptual sobre el mismo, se registraron fallas cuando se les solicitó organizar como ensayo académico la documentación relevada previamente sobre el tema elegido. De un modo similar, se hallaron desaciertos en cuanto a la utilización de las conversaciones con el artista. En algunos casos faltó una mirada selectiva, crítica, interpretativa de las mismas, reduciéndose las presentaciones del cuarto trabajo práctico (TP4) a la reproducción de la entrevista.

Empero, existieron tanto excepciones a estas derivaciones como reorientaciones que se adecuaron a lo exigido a partir de sucesivas correcciones y coloquios alumno-docente. En este sentido, puede inferirse que los estudiantes carecían de experiencias previas en este tipo de tareas (uso de entrevistas para hacer una actividad; confeccionar un ensayo; ordenar los datos de una investigación), pues esta situación no se había registrado en cursos anteriores en los cuales se implementó este mismo proyecto. Se adicionan, además, ciertas dificultades en la comunicación escrita, relativas a la expresión de ideas propias y a la presencia de marcas de oralidad, modismos o lenguaje cotidiano.

Existen, sin embargo, dos aspectos sumamente positivos a destacar. En primer lugar, la motivación que despertó en los estudiantes la captación de tendencias y cuestiones actuales dentro de sus disciplinas. El descubrimiento de información o de prácticas novedosas como así también de producciones y discursos artísticos contemporáneos generó entusiasmo y favoreció procesos de comprensión y de integración conceptual. Segundo, la concreción del proyecto de exhibición artística (en el TP5) desplegó aportaciones originales y creativas, en sus dos vertientes: las tareas de curaduría como de diseño. 
En las instancias de dinámica grupal, se detectaron algunos puntos débiles. Si bien los alumnos mostraron organización y buen rendimiento en el trabajo grupal, se notaron, entre pocos grupos de estudiantes, algunos momentos de irregular atención respecto a las exposiciones orales entre los compañeros. De ello puede inferirse cierta "inmadurez académica" en los alumnos en relación a situaciones más informales de trabajo, como la relativa importancia otorgada al debate o a las contribuciones que pueden obtenerse del escuchar y dialogar con los pares. Otro aspecto a considerar es el manejo del tiempo. Aproximadamente un $15 \%$ de los estudiantes no mostraron una administración adecuada de los tiempos, cuestión que, si bien no incidió en la calidad de las presentaciones, es conveniente atender, con el fin de que el alumno logre programar sus actividades de modo que el rendimiento sea más efectivo.

b) Articulación del ensayo final

Los resultados obtenidos en las primeras redacciones del ensayo mostraron cierta disparidad. En esta dirección, se han observado fundamentalmente extremos respecto a la extensión (de dos carillas a veinte) como al carácter de las presentaciones (más descriptivo o más reflexivo). Estos aspectos, sin embargo, han permitido un feedback entre docentetutor y estudiante que, en muchos casos, facilitó la propia autocrítica del alumno sobre su trabajo. Asimismo, cabe destacar el esfuerzo de gran parte de los alumnos en la apropiación y elaboración de los marcos conceptuales brindados en las clases magistrales. En este sentido, es necesario aclarar que las clases teóricas finales versaron sobre las últimas tendencias y prácticas estéticas actuales y las aproximaciones conceptuales que abordan los proyectos artísticos emergentes y las formas culturales experimentales. Es así que varios trabajos se animaron a encarar la indagación de las experiencias derivadas de las tendencias o cuestiones elegidas desde estas nuevas perspectivas.

En síntesis, mediante la experiencia implementada, los estudiantes, con distintos grados de desarrollo y profundización, han logrado: - Formular preguntas, identificar una tendencia como punto de partida de una investigación.

- Rastrear y analizar datos.

- Seleccionar información (qué es relevante y qué es prescindible).

- Realizar entrevistas.

- Confrontar opiniones, textos e imágenes.

- Extraer conclusiones; revisar sus ideas. - Realizar un escrito ensayístico y su defensa como examen final.

De los estudiantes participantes, el 100\% estaba en condiciones de rendir en la primera fecha posterior a la cursada el examen final.

La evaluación de la experiencia

En cuanto a la focalización en el estudiante, aunque combinada con métodos tradicionales (como en algunas clases magistrales organizadas en secuencias progresivas lineales), esta experiencia ha resultado de interés como motivadora de aprendizajes autónomos. Ha logrado que los estudiantes se enfrentaran con cuestiones 
reales; que pudieran abordarlas mediante conocimientos previos, experienciales y saberes adquiridos durante el desarrollo de la materia. Ha implicado una cursada intensiva por la clase y variedad de tareas y actividades planteadas, como por los niveles de compromiso exigidos. Cabe señalar también que debido a su carácter versátil y abierto, la propuesta pudo amoldarse a los tiempos de clase y al número de estudiantes participantes, con algunos recortes temáticos. Se ajustó asimismo de forma satisfactoria a las características particulares del grupo de alumnos, a sus intereses y saberes previos, a sus ritmos de trabajo; de allí, por ejemplo, la incorporación de algunas actividades no previstas, como el "parcial" ya descripto. Del mismo modo, el proyecto es factible de ser adaptado a otros contextos dentro de la educación superior. Esto se sostiene, en principio, porque la mirada desde el arte posibilita distintas maneras de captar y analizar la realidad; además, puede vincularse con otras áreas del saber incluso diversas al arte mismo. En segundo lugar, se advierte sobre el nivel educativo de implementación, dado el grado de exigencia y la complejidad de secuencias de trabajo escalonadas.

Otro aspecto a considerar es la percepción positiva que los alumnos han manifestado sobre el trabajo. Más allá de los distintos grados de calidad y elaboración que cada ensayo exhibe, es de destacar los entusiasmos, tímidos al inicio cuando la propuesta parecía una empresa compleja, aunque este carácter nunca fue vivenciado como un obstáculo. Desde "descubrí un mundo nuevo" hasta aquellas profundizaciones que les permitieron tomar conciencia de cuestiones cotidianas y de relevancia actual, se evidenció entre los alumnos una valoración favorable sobre la experiencia.

Por último, esta propuesta áulica parte de la combinación de estrategias tradicionales con perspectivas metodológicas de cuño constructivista, centradas en el estudiante y en la autorregulación de los aprendizajes. En base al análisis de los resultados y del proceso formativo que implicó su aplicación, es posible sostener que este tipo de diseño donde se combinan ambas ópticas didácticas, se ha revelado como una buena configuración. Es sabido que los alumnos tienden a preferir las clases expositivas o tradicionales; éstas les proveen, según la percepción de los propios estudiantes, mayor seguridad y estabilidad en la organización de los contenidos, para luego poder emprender un proyecto autónomo. A su vez, la riqueza de la propuesta desarrollada reside justamente en la recurrencia a otras prácticas didácticas que tienen en cuenta los procesos del aprender de los alumnos, buscando favorecer instancias de reflexión y construcción del saber.

Notas

1. Ver Catálogo de Asignaturas, Facultad de Diseño y Comunicación, Universidad de Palermo. Disponible en: http://www.palermo.edu/dyc/cat/020451.html.

\section{Provista por la Facultad de Diseño y Comunicación.}

3. Ensayos sobre la imagen 2011, Facultad de Diseño y Comunicación, Universidad de Palermo. Recuperado el 10 de junio de 2011. Disponible en:

http://fido.palermo.edu/servicios_dyc/normas_audiovisual/ensayos_imagen.php 4. Ibídem.

5. Al respecto confrontar M. C. Rinaudo y D. S. Donolo (2007), Investigación en educación. Aportes para construir una comunidad más fecunda. Buenos Aires: La Colmena. 
6. Ver Cronograma en Figura B en Anexo.

7. Esta modalidad se circunscribe a las entregas y consultas vía e-mail.

8. Ver Figura A en el Anexo.

9. Son las Guías del Block de Materiales de Cátedra.

10. Knowles, M. S. (1975) Self-Directed Learning: A Guide for Learners and Teachers. New York: Cambridge Book Company.

11. Ver Figura A en Anexo.

12. Gardner, H. (1995), Mentes creativas, Barcelona: Paidós, y (1993), La mente no escolarizada, Barcelona: Paidós.

13. Tishman, Sh., Perkins, D. y Jay, E. (1995), The Thinking classroom. Learning and teaching in a culture of thinking, New York: Allyn \& Bacon.

14. Aguilera Pupo, Eleanne; Ortiz Torres, Emilio (2009) "Las investigaciones sobre los estilos de aprendizaje y sus modelos explicativos", Revista Estilos de Aprendizaje, 4 (4) Universidad Nacional de Educación a Distancia. Disponible en: http://www.uned.es/revistaestilosdeaprendizaje/numero_4/Artigos/lsr_4_articulo2.pdf 15. LópezVargas, Omar, Hederich-Martínez, Christian. Camargo-Uribe, Ángela (2011) "Estilo cognitivo y logro académico", Educación y Educadores, 14, (1). Facultad de Educación, Universidad de la Sabana, Colombia, p. 72.

16. López-Vargas, Omar, Hederich-Martínez, Christian. Camargo-Uribe, Ángela (2011) "Estilo cognitivo y logro académico", Educación y Educadores, 14, (1) Facultad de Educación, Universidad de la Sabana, Colombia, p. 77.

Bibliografía

Aguilera Pupo, E. y Ortiz Torres, E. (2009). Las investigaciones sobre los estilos de aprendizaje y sus modelos explicativos, Revista Estilos de Aprendizaje, 4 (4) Universidad Nacional de Educación a Distancia. Disponible en: http://www.uned.es/revistaestilosdeaprendizaje/ numero_4/Artigos/lsr_4_articulo2.pdf Gardner, H. (1995). Mentes creativas, Barcelona: Paidós.

(1993). La mente no escolarizada, Barcelona: Paidós.

Litwin, E. (1997). Las configuraciones didácticas. Una nueva agenda para la enseñanza superior, Buenos Aires: Paidós Educador.

López-Vargas, O., Hederich-Martínez, C., Camargo-Uribe, A. (2011). Estilo cognitivo y logro académico, Educación y Educadores, 14, (1), 6782. Facultad de Educación, Universidad de la Sabana, Colombia.

Tishman, Sh., Perkins, D. y Jay, E. (1995). The Thinking classroom. Learning and teaching in a culture of thinking, New York: Allyn \& Bacon 
Bibliografía general de la planificación de la asignatura

Gombrich, E. (1992). Lo que nos cuentan las imágenes, Madrid: Debate.

Laddaga, R. (2006). Estética de la emergencia, Rosario: Adriana Hidalgo Editora.

López Anaya, J. (1995). El arte en un tiempo sin dioses, Buenos Aires: Almagesto.

Hauser A. (2002). Historia social de la literatura y el arte: desde la prehistoria hasta el barroco, Buenos Aires: Debate.

Read, H. (1988). Historia de la pintura moderna, Barcelona: Del Serbal.

Romero Brest, J. (1978). La pintura del siglo XX, México: Fondo de Cultura Económica.

Droste, M. (1991). Bauhaus, Buenos Aires: Taschen.

Lucie-Smith, E. (1995). Movimientos artísticos desde 1945, Barcelona: Destino.

1.1. Detección y abordaje de problemas o tendencias actuales en el arte y el diseño fue publicado de la página 135 a página156 en Cuadernos del Centro de Estudios de Diseño y Comunicación Nㅜ 63 